\title{
High dose interstitial brachytherapy for treatment of carcinoma of the lip as an alternative to surgery: a case report
}

\author{
Percy Torres-Quispe ${ }^{1,2, a}$ (iD, Lissett Jeanette Fernández-Rodríguez $3,4,$, ,b \\ , Yaowen Zhang $5,6, t, c$ \\ and Angeles Rovirosa-Casino $5,6, \mathrm{~d}$
}

${ }^{1}$ Department of Oncology and Radiotherapy, Hospital Nacional Edgardo Rebagliati Martins, Av. Edgardo Rebagliati 490, Jesús María, Lima 15072, Perú 2Universidad Nacional San Antonio Abad del Cusco, Av. de La Cultura 773, Cusco 08000, Perú

${ }^{3}$ Diagnosis and Treatment Assistance Department, Hospital de Alta Complejidad Virgen de la Puerta, M.Bastidas 309, La Esperanza, La Libertad 13013, Perú

${ }^{4}$ Universidad Privada Antenor Orrego, Avenida América Sur 3145, Trujillo, La Libertad 13008, Perú

${ }^{5}$ Radiation Oncology Service, Hospital Clinic i Provincial de Barcelona, C. de Villarroel, 170, Barcelona 08036, Spain

${ }^{6}$ Fonaments Clinics Department, Faculty of Medicine, Universitat de Barcelona, Casanova, 143, Barcelona 08036, Spain

*Current affiliation: Department of Medicine, Hospital de Alta Complejidad Virgen de la Puerta, M.Bastidas 309, La Esperanza, La Libertad 13013, Perú

†Current affiliation: Cancer Center, Henan Provincial People's Hospital, Zhengzhou 450008, China

a https://orcid.org/0000-0003-1434-1925

b https://orcid.org/0000-0002-4357-4261

chttps://orcid.org/0000-0002-2379-6174

d $\underline{\text { https://orcid.org/0000-0002-7832-334X }}$

\section{Abstract}

Lip cancer (LC) is the most common cancer of the oral cavity and is the second most common in the head and neck. Brachytherapy (BT) is a good treatment option for this type of cancer because it administers high doses of radiation to the target. BT has similar cure and survival rates as surgery for the same type of cancer, but it often produces more favourable aesthetic results, especially when the tumour is treated in its early stages. We present a case of a patient diagnosed with stage II lower LC who refused surgical treatment. Instead, highdose-rate interstitial BT was performed with ${ }^{192}$ Ir. A 2-year post-treatment follow-up indicated there were neither serious complications nor recurrence of cancer during that period.

Keywords: brachytherapy, lip neoplasm, iridium radioisotopes, squamous cell carcinoma

\section{Background}

Lip cancer (LC) is the most common malignancy of the oral cavity and is the second most common in the head and neck. It has a worldwide age-standardised incidence of 5.8 per 100,000 persons per year and it affects predominately males [1]. LC is associated with high solar exposure, tobacco and alcohol use, poor oral hygiene, lip trauma, immunosuppression and precancerous lesions [2-4]. Nearly all (90\%) LC is localised in the lower lip (LL), and the type of cancer most found is well-differentiated squamous cell carcinoma, followed by basal cell tumours [4].

LC tends to form tumours that are easily visualised and localised, which grow slowly, permitting early diagnosis. Therefore, LC has a high rate of survival among those treated [3]. Lymphatic spreading in the cancer's early stages rarely occurs. At diagnosis, only $5 \%-10 \%$ of cases have lymph node metastasis, with submental (level la) and submandibular (level Ib) lymph nodes being the most affected [4]. More distant metastases are also rare but
Correspondence to: Percy Torres-Quispe Email: percyberm6@gmail.com

ecancer 2021, 15:1297

https://doi.org/10.3332/ecancer.2021.1297

Published: $30 / 09 / 2021$

Received: 12/04/2021

Publication costs for this article were supported by ecancer (UK Charity number 1176307).

Copyright: (c) the authors; licensee ecancermedicalscience. This is an Open Access article distributed under the terms of the Creative Commons Attribution License (http:// creativecommons.org/licenses/by/4.0), which permits unrestricted use, distribution, and reproduction in any medium, provided the original work is properly cited. 
have been found with more advanced tumours. Prognostic factors include tumour size, lymph node infiltration, perineural and lymphovascular invasion and age, with the youngest having poorer prognoses [4-6]. The 5-year survival rate is between $90 \%$ and $95 \%$ at stage T1, 75\%-85\% at stage T2, with a large decrease for T3-T4 [3].

Both surgery and brachytherapy (BT) play important roles in LC treatment, given that these treatments alone or in combination with external radiotherapy are indicated in over $90 \%$ of cases [4]. High-dose-rate interstitial brachytherapy (HDRIB) is frequently used to treat LC. This procedure involves placing applicators in the tumour and then repeatedly placing a radiation source within the applicator. The applicators are removed upon treatment completion [5]. ${ }^{192} \mathrm{Ir}$ is frequently used in HDRIB due to its high specific activity and photon energy, ensuring homogenous treatment of the target.

HDRIB has a number of advantages over a more radical surgical approach. It is painless when used with local anaesthesia or intravenous analgesics, provides a focused dose to the tumour bed with minimal damage to healthy tissue and the rest of the body, has low toxicity (no permanent contact with radioisotope source) and preserves anatomy. Furthermore, HDRIB has a good aesthetic outcome, reduces the risk of surgical microstomia and reduces radiation exposure to health personnel [5, 7-9]. However, developing a treatment plan, acquiring radioisotopes and appropriate software, and ingrained traditional approaches to treating LC present a challenge to adopting HDRIB in hospitals located in less developed countries, like Peru. Therefore, we present one of the first cases of LC treated with HDRIB in Peru, which required a collaborative approach between the patient and physicians to increase treatment options for LC.

\section{Patient information}

A 53-year-old male from Lima, Peru, with a six cigarette-per-day smoking habit for 20 years was admitted for evaluation of an ulcerative lesion on the left side of the LL. The lesion was previously diagnosed as well-differentiated infiltrating squamous cell carcinoma in a different health centre. He stated that the lesion had been present for 2 years. A $1.5 \times 2.5 \mathrm{~cm}$ nodule adjacent to the lesion was revealed upon palpitation (Figure 1). No enlarged lymph nodes or adenopathies were found upon palpation or ultrasound. The patient had no additional pathological antecedents of interest.

A computed tomography (CT) scan revealed premandibular cutaneous laminar thickening of a likely reactive inflammatory nature and normal lungs. Swollen lymph nodes were also observed. Microscopic review of biopsies confirmed the diagnosis. The cancer was staged at T2NOMO according to TNM guidelines [4].

The patient was given a choice of surgery or HDRIB to treat the neoplasm. He opted for HDRIB because he preferred to avoid cuts or scars on his face. The patient was admitted to the hospital and given clindamycin $(600 \mathrm{mg})$ and bicarbonate mouth rinses every 8 hours.

Under local anaesthesia, five equidistant metallic needles were inserted through the left side of the LL with the assistance of plastic templates (Figure 2). Plastic catheters were pulled through the tissue as the needles were withdrawn. The catheters were stabilized in the patient with the use of white radiolucent buttons (Nucletron, $1.9 \mathrm{~mm}$ ) (white plastic circles, Figure 3). Placement of the needles and catheters followed the Paris system $[4,8]$.

After the catheters were inserted, a CT image was taken of the lesion, adjacent nodule and surrounding tissues. This image was used to plan HDRIB treatment (Figure 4, Table 1). For simulation, the gross tumoural volume included both the lesion and nodule, and the clinical tumoural volume (CTV) was considered to be the same with a $1 \mathrm{~cm}$ margin. Radiation dose was administered according to a dosimetric study that considered the surrounding organs [10].

Following the treatment plan, ${ }^{192}$ Ir pellets were placed in the catheters for a series of nine fractions over 5 days. On the first day of treatment, the patient received one fraction of $5.00 \mathrm{~Gy}$. For the next 4 days, two daily fractions of 5.00 Gy were administered at an interval of 6 hours providing a total equieffective dose $(E Q D 2)_{(\alpha / \beta=10)}$ of $56 \mathrm{~Gy}$. A dental shield made of lead covered in paraffin was used to protect the gingiva during the HDRIB treatments. After HDRIB was complete, the plastic catheters were removed.

One month post treatment, the patient received his first follow-up. The patient had localised acute radiation toxicity with bleeding ulcerative mucositis at the treatment site. He was prescribed analgesics, anti-inflammatory drugs and a mouthwash to treat his symptoms. The mouthwash was prepared in-house and contained $30 \mathrm{~mL}$ lidocaine gel $(2 \%), 12 \mathrm{~mL}$ nystatin $(100,000 \mathrm{IU} / \mathrm{mL}), 60 \mathrm{~mL}$ sulfamethoxazole and trimethoprim ( $40 \mathrm{mg} / \mathrm{mL}$ and $8 \mathrm{mg} / \mathrm{mL}$ ), $120 \mathrm{~mL}$ of aluminium hydroxide/magnesium hydroxide with simethicone and $1 \mathrm{~L}$ of distilled water. 


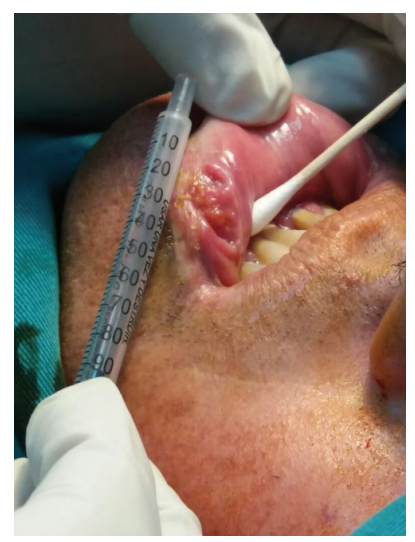

Figure 1. Photograph of the ulcerative mucosal lesion of the lower left lip before treatment.

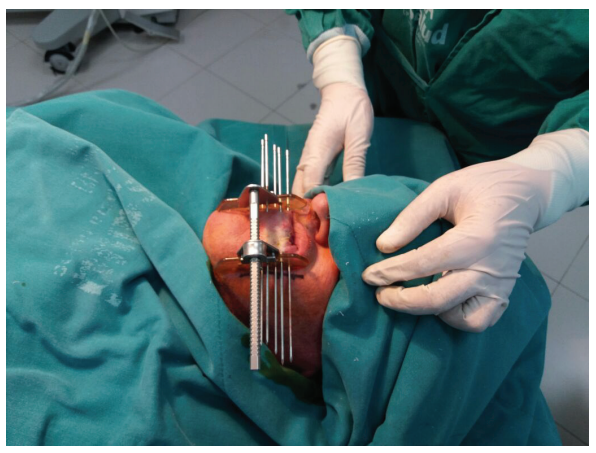

Figure 2. Placement of metal needles according to the Paris system is assisted by clear plastic templates held in place by a metal frame.

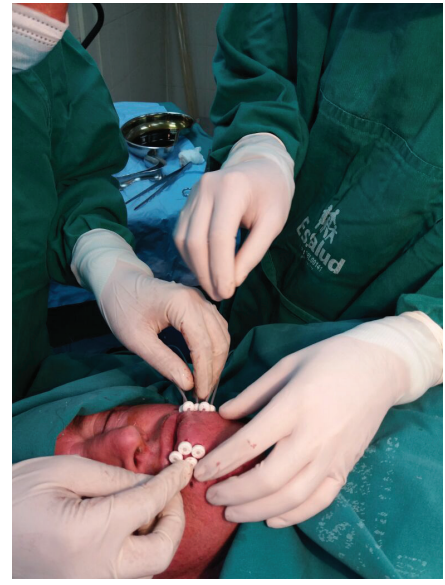

Figure 3. Stabilization of BT catheters using radiolucent buttons in the LL. 

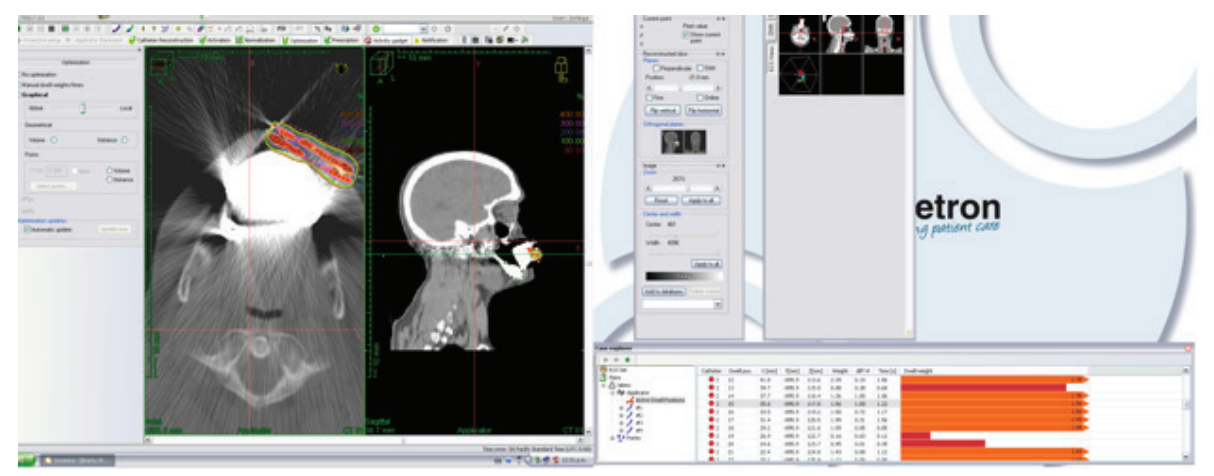

Figure 4. Simulation of HDRIB with ${ }^{192}$ Ir for irradiation of the patient's tumour.

Table 1. Treatment plan parameters.

\begin{tabular}{|c|c|}
\hline Treatment details & HDRIB to the lower left lip \\
\hline BT dosage & $\begin{array}{l}45.0 \mathrm{~Gy} \text { to the tumour in nine fractions, } 5.00 \mathrm{~Gy} \text { per fraction. Dose } \\
\text { planned to cover the PTV is } 90 \% \text { of } 45 \mathrm{~Gy}=40.5 \mathrm{~Gy} \text { total dose in } 4.5 \mathrm{~Gy} \\
\text { per session.EQD2 for } 100 \%=56 \mathrm{~Gy} \text {, for } 90 \% \text { is } 45 \mathrm{~Gy} \text {, assuming } \alpha / \beta=10\end{array}$ \\
\hline Target definition & $\begin{array}{l}\text { Gross tumour volume }=\text { CTV } \\
C T V+1 \mathrm{~cm}=\text { PTV } \\
\text { PTV volume }=9.18 \mathrm{~cm}^{3}\end{array}$ \\
\hline Number of catheters & 5 \\
\hline $\begin{array}{l}\text { Treatment plan } \\
\text { parameters }\end{array}$ & $\begin{array}{l}\mathrm{D}_{90}=4.50 \mathrm{~Gy} \\
\mathrm{~V}_{100}=1.19 \mathrm{~cm}^{3} \\
\mathrm{~V}_{150}=1.10 \mathrm{~cm}^{3} \\
\mathrm{~V}_{200}=0.64 \mathrm{~cm}^{3}\end{array}$ \\
\hline $\begin{array}{l}\text { Calculated dosage } \\
\text { to organs at risk per } \\
\text { session }\end{array}$ & $\begin{array}{l}\text { Lower jaw: } 0.7895 \mathrm{~Gy} \\
\text { Spinal cord: } 0 \mathrm{~Gy} \\
\text { Left eye: } 0.2588 \mathrm{~Gy} \\
\text { Right eye: } 0.1200 \mathrm{~Gy} \\
\text { Thyroid gland: } 0 \mathrm{~Gy} \\
\text { Gingiva: } 0.9986 \mathrm{~Gy}\end{array}$ \\
\hline
\end{tabular}

PTV: planning target volume

At his second follow-up, a month later, the ulcer measured $1.5 \times 1.5 \mathrm{~cm}$ with an indurated area. The LL was epithelialised and tumour free at his third follow-up, a month later. A final evaluation, conducted 2 years after treatment, revealed that the patient was asymptomatic and disease-free. However, mild atrophy and skin hypopigmentation were observed as long-term side effects of the treatment. The patient stated that he was pleased with the results and aesthetic outcome of his procedure (Figure 5).

\section{Discussion}

In the present case, LC was detected at a relatively early stage, so surgery or radiotherapy are both viable options with similar survival rates in the case of tumours larger than $2 \mathrm{~cm}$. However, it has been shown that surgery for LC can cause undesirable side effects such as scarring, loss of lip function and microstomia [11-12]. The recommendations of the Groupe Européen de Curiethérapie (GEC) and the European Society for Radiotherapy \& Oncology (ESTRO) for the use of HDRIB are LC with a thickness $\geq 5 \mathrm{~mm}$ with an irregular surface, 8-12 mm distance between catheters that must be at least $3 \mathrm{~mm}$ below the skin surface to avoid complications. Additionally, it is necessary to use CT to define the CTV [8]. 


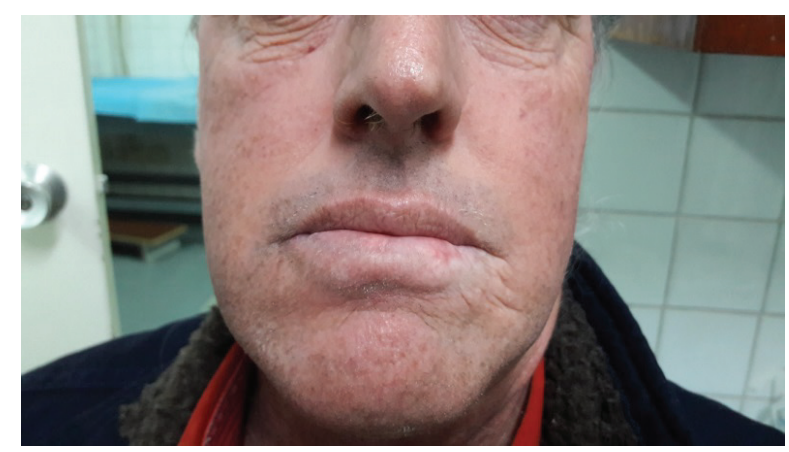

Figure 5. Two-year post-treatment result, indicating mild atrophy and hypopigmentation. The patient was pleased with the aesthetic result.

Table 2. Comparison of different BT alternatives in LC treatment.

\begin{tabular}{|l|l|l|l|}
\hline \multirow{2}{*}{\multicolumn{2}{|c|}{ Characteristics }} & \multicolumn{1}{c|}{ BT type } \\
\cline { 2 - 4 } & \multicolumn{1}{|c|}{ LDRIB } & \multicolumn{1}{c|}{ PDR } & \multicolumn{1}{c|}{ HDRIB } \\
\hline Dose activity (Gy/h) & $0.4-2$ & $2-12$ & $>12$ \\
\hline Indications & $\begin{array}{l}\text { Tumours T1-T2. } \\
\text { Positive surgical margins } \\
\text { Post-surgical relapse. }\end{array}$ & $\begin{array}{l}\text { Tumours T1-T3. } \\
\text { Positive surgical margins } \\
\text { Post-surgical relapse. }\end{array}$ & $\begin{array}{l}\text { Tumours T1-T2, T4 } \\
\text { (low-volume) Positive } \\
\text { surgical margins } \\
\text { Post-surgical relapse. }\end{array}$ \\
\hline Contraindications & Bone infiltration & Bone infiltration & Bone infiltration \\
\hline Local control (\%) in 5 years & $94 \%-96.6 \%$ & $95 \%$ & $>95 \%$ \\
\hline
\end{tabular}

Radiotherapy for LC may be administered using an external radiation source, by low-dose-rate interstitial brachytherapy (LDRIB), pulsed dose rate (PDR) brachytherapy [13] or by HDRIB (Table 2) [12]. The difference between these radiotherapy treatments is activity of the implants (0.4-2 Gy/h, 2-12 Gy/h and > $12 \mathrm{~Gy} / \mathrm{h}$, respectively) and the length of time the patient is exposed to the radioactive sources [12]. Indications for their use are similar and include T1 to T2-staged tumours, positive surgical margins and post-surgical recurrences. They are contraindicated in cases with bone involvement or significant tissue loss [4]. Additionally, BT does not seem to be indicated for adenocarcinomas, lymphomas, melanomas and sarcomas, except for rhabdomyosarcomas [12]. In cases of LC with advanced tumours or with lymph node involvement, external radiotherapy that includes the primary tumour and neck with a dose up to 45 to 50 Gy followed by BT is the preferred route [4].

HDRIB has the same efficacy as LDRIB for LC. In a retrospective study, where 103 patients were followed for an average of 3.1 years, Ghadjar et al [14] found that there was no difference in survival rate or acute or long-term toxicity between either technique. Guinot et al [15] compared the same methods in a similar study that involved 99 patients. Likewise, the study resulted in similar conclusions: long-term local control and disease-free survival were similar. However, fewer complications were observed with HDRIB treatment. An additional advantage is that HDRIB allows for optimising dose distribution [15].

In HDRIB, the equivalent dose per fraction is usually 4.5-5 Gy in approximately nine fractions distributed at two fractions daily for 5 days. The planning of HDRIB with ${ }^{192}$ Ir follows the Paris System. HDRIB is a useful treatment option for patients with inoperable T1-T2-staged tumours or those who reject surgery. Additionally, HDRIB offers excellent aesthetic and functional results, low toxicity and local control between $88 \%$ and $100 \%$ of cases [15-18]. Acute toxicity is most commonly grade 1 and requires topical medicine. Long-term side-effects include hypopigmentation, telangiectasias and in some cases a certain degree of fibrosis. However, these are very rare: over $90 \%$ of patients treated with HDRIB for LC have satisfactory functional and cosmetic results, and most patients who underwent the procedure would recommend it $[8,19,20]$. 


\section{Conclusions}

HDRIB has been proven to be useful in treating LC and other tumours of the oral cavity either alone or after surgery with compromised margins, or with external radiotherapy.

The present study adds to the growing body of evidence that HDRIB using ${ }^{192}$ Ir is effective in patients with early-stage LC who do not wish to undergo surgery or have comorbidities that make surgical revision of the tumour unacceptable. Curative EQD2 dose ranges between 50 and

$60 \mathrm{~Gy}$. In the present case, an EQD2 $(\alpha / \beta=10)$ dose of $56 \mathrm{~Gy}$ in HDRIB resulted in disappearance of the cancerous lesion with few side effects, minimal toxicity and acceptable aesthetics.

Furthermore, this case reports one of the first treatments of LC with HDRIB in Peru, thus overcoming challenges of administrative inertia and logistics. This case also shows that good doctor-patient collaboration can occur in under-resourced environment and patients can receive a high standard of care. This requires considering the patient's desires and likely outcomes of treatment. Although surgical resection is still practiced in similar cases, the successful treatment of this patient has already encouraged doctors to more regularly use HDRIB as an alternative to surgery based on patient preference or when comorbidities complicate surgery.

\section{Conflicts of interest}

The authors declare that they have no economic or non-economic conflicts of interest in the publication of this article.

\section{Funding statement}

The authors received no funding for the research and publication of this study.

\section{Authors' contributions}

PTQ - radiation oncologist who performed the BT procedure and supervised the treatment of the patient.

YZ - radiation oncologist who contributed to writing the discussion section.

LJFR - radiation oncologist who recompiled the case, wrote the manuscript and prepared the figures.

ARC - radiation oncologist, BT specialist who mentored all participants, senior researcher.

\section{Acknowledgments}

The authors wish to thank Juan Carlos Ortega Basilio, Medical Physicist of the Radiotherapy Department, Hospital Edgardo Rebagliati Martins, Lima, Peru.

\section{References}

1. Bray F, Ferlay J, and Soerjomataram I, et al (2018) Global cancer statistics 2018: GLOBOCAN estimates of incidence and mortality worldwide for 36 cancers in 185 countries CA Cancer J Clin 68 394-424 https://doi.org/10.3322/caac.21492 PMID: 30207593

2. Mut A, Guinot JL, and Arribas L, et al (2016) High dose rate brachytherapy in early stage squamous-cell carcinoma of the lip Acta Otorrinolaringol Esp 67 282-287 https://doi.org/10.1016/j.otorri.2015.12.003 PMID: 27063585 
3. Ayerra AQ, Mena EP, and Fabregas JP, et al (2010) HDR and LDR brachytherapy in the treatment of lip cancer: the experience of the Catalan Institute of Oncology J Contemp Brachyther 2 9-13 https://doi.org/10.5114/jcb.2010.13717

4. Rovirosa-Casino A, Planas-Toledano I, and Ferre-Jorge J, et al (2006) Brachytherapy in lip cancer Med Oral Patol Oral Cir Bucal 11 E223E229 PMID: 16648757

5. Guinot JL, Arribas L, and Chust ML, et al (2003) Lip cancer treatment with high dose rate brachytherapy Radiother Oncol 69 113-115 https://doi.org/10.1016/S0167-8140(03)00271-8 PMID: 14597364

6. Boddie AW Jr, Fischer EP, and Byers RM (1977) Squamous carcinoma of the lower lip in patients under 40 years of age South Med J 70 711-715 https://doi.org/10.1097/00007611-197706000-00022 PMID: 877622

7. Kakimoto N (2019) High-dose-rate brachytherapy for oral cancer Brachytherapy: Techniques and Evidences eds J Yoshioka Itami, M Oguchi, and T Nakano (Singapore: Springer) https://doi.org/10.1007/978-981-13-0490-3_18

8. Guinot JL, Rembielak A, and Perez-Calatayud J, et al (2018) GEC-ESTRO ACROP recommendations in skin brachytherapy Radiother Oncol 126(3) 377-385 https://doi.org/10.1016/j.radonc.2018.01.013 PMID: 29455924

9. Unsal Tuna EE, Oksüzler O, and Ozbek C, et al (2010) Functional and aesthetic results obtained by modified Bernard reconstruction technique after tumour excision in lower lip cancers J Plast Reconstr Aesthet Surg 63 981-987 https://doi.org/10.1016/j.bjps.2009.02.073

10. Thanh Pham T, Cross S, and Gebski V, et al (2015) Squamous cell carcinoma of the lip in Australian patients: definitive radiotherapy is an efficacious option to surgery in select patients Dermatol Surg 41 219-225 https://doi.org/10.1097/DSS.0000000000000240 PMID: 25627631

11. Stucker FJ and Lian TS (2004) Management of cancer of the lip Oper Tech Otolaryngol Head Neck Surg 15 226-233 https://doi. org/10.1016/j.otot.2004.06.003

12. Mazeron JJ, Ardiet JM, and Haie-Méder C, et al (2009) GEC-ESTRO recommendations for brachytherapy for head and neck squamous cell carcinomas Radiother Oncol 91 150-156 https://doi.org/10.1016/j.radonc.2009.01.005 PMID: 19329209

13. Johansson B, Karlsson L, and Hardell L, et al (2011) Long term results of PDR brachytherapy for lip cancer J Contemp Brachyther $365-69$ https://doi.org/10.5114/jcb.2011.23199

14. Ghadjar P, Bojaxhiu B, and Simcock M (2012) High dose-rate versus low dose-rate brachytherapy for lip cancer Int J Radiat Oncol Biol Phys 83 1205-1212 https://doi.org/10.1016/j.ijrobp.2011.09.038

15. Guinot JL, Arribas L, and Tortajada MI, et al (2013) From low-dose-rate to high-dose-rate brachytherapy in lip carcinoma: equivalent results but fewer complications Brachytherapy 12 528-534 https://doi.org/10.1016/j.brachy.2013.05.007 PMID: 23850275

16. Farrús B, Pons F, and Sánchez-Reyes A, et al (1996) Quality assurance of interstitial brachytherapy technique in lip cancer: comparison of actual performance with the Paris system recommendations Radiother Oncol 38 145-151 https://doi.org/10.1016/01678140(95)01685-6 PMID: 8966227

17. Finestres-Zubeldia F, Guix-Melcior B, and Cloquell-Damian A, et al (2005) Treatment of the carcinoma of the lip through high dose rate brachytherapy Med Oral Patol Oral Cir Bucal 10 17-20

18. Vavassori A, Gherardi F, and Colangione SP, et al (2012) High-dose-rate interstitial brachytherapy in early stage buccal mucosa and lip cancer: report on 12 consecutive patients and review of the literature Tumori 98 471-477 https://doi.org/10.1177/030089161209800412 PMID: 23052164

19. Guibert M, David I, and Vergez S, et al (2010) Brachytherapy in lip carcinoma: long-term results Int J Rad Oncol Biol Phys 81(5) E839E843 https://doi.org/10.1016/j.ijrobp.2010.10.031

20. El Ayachy R, Sun R, and Ka K, et al (2021) Pulsed dose rate brachytherapy of lip carcinoma: clinical outcome and quality of life analysis Cancers 13(6) 1387 https://doi.org/10.3390/cancers13061387 PMID: 33808535 PMCID: 8003123 